\title{
International conference in Helsinki ponders accessibility
}

\author{
Making Cultural Heritage Truly Inclusive - Prospects of Accessibility \\ in Nordic Museums 11-12 0ctober 2007, the National Museum \\ of Finland
}

Elina Anttila*, Sari SalovaAra* and Leena Tokila*

\begin{abstract}
This article focuses on questions that emerged at the "Making Cultural Heritage Truly Inclusive" conference, which was held in Helsinki on 11-12 October 2007. The theme of the conference was the Nordic principle of equality as seen in relation to the cultural heritage sector. The participants numbered about 140 cultural heritage workers from the Nordic countries and elsewhere in Europe. In addition to representatives of the museum sector, the invited speakers included future researchers and policy makers.

At the conference, museums were seen as exerting a social influence. The first part of the conference examined accessibility strategies and the challenges and expectations they engendered in the projected Nordic future. The second part dealt with the potential of the shared Nordic cultural heritage for reflecting a multicultural society. The third part of the conference focused on future challenges, which were identified as including virtual communities for young people, and the importance of considering an ageing population. The conference was part of the Tillgänglighetsnätverk för museer i Norden (Accessibility networks for museums in the Nordic countries) project, which, over the past few years, has been creating a cooperation network to enable Nordic culture sector organisations that are interested in accessibility issues to exchange experiences.
\end{abstract}

Key words: Accessibility, museums, cultural heritage, Nordic conference, new target groups.

Nordic values include the promotion of equality. All citizens are equally entitled to access to the cultural heritage and to produce, receive and understand culture, its content and meanings. How can the cultural heritage sector cope with this challenge? More than 140 people working in the cultural heritage sector in Finland, the other Nordic countries, the Baltic States, Russia, the UK and Spain gathered in Helsinki in October this year to consider these questions. The conference was part of the Tillgänglighetsnätverk för museer $i$ Nor- 
den (Accessibility networks for museums in the Nordic countries) project, which, over the past few years, has been creating a network of cooperation to enable Nordic culture sector organisations that are interested in accessibility issues to exchange experiences.

At the conference, museums were seen as exerting a social influence. In addition to experts in the museum sector, conference participants included future researchers and representatives of interest organisations. The first part of the conference examined accessibility strategies and the challenges and expectations they engendered in the projected Nordic future. One of the speakers who dealt with this theme was Stefan Wallin, Finland's Minister of Culture and Sports. The second part dealt with the potential of the shared Nordic cultural heritage for reflecting a multicultural society. The keynote speaker was Professor Richard Sandell of Leicester University, who examined museums in their role of promoting tolerance. The third part of the conference focused on future challenges, which were identified as including virtual communities for young people, and the importance of considering an ageing population. These themes were addressed by Frans Mäyrä, Professor of Hypermedia, and Anne Ågotsnes, Senior Scientific Adviser, Bergen City Museum/Bryggens Museum, Norway.

\section{OBSERVATIONS, THOUghtS, QUESTIONS}

How should museums respond to social trends and the way they are reflected, for instance, as changes in the relationships between specific demographic groups? Immigration, the ageing population and the polarisation of social welfare are giving rise to new demographic groups that must be brought into contact with the cultural heritage. Alongside the physical obstacles to this, there emerged attitudes and other mental obstacles that can often be difficult to identify. Is it possible to consider all these matters in cultural services; is equal access possible in practice?

The prevailing definition of welfare in itself gives rise to inequality in the cases where medical science is applied in order to reduce an individual's physical or mental limitations to access rather than to making services more accessible. All problems should be viewed as limitations on the part of society rather than as an inability on the part of the individual.

However, can the state budget sustain the cost of really making the cultural heritage accessible? According to the "Design for All" model, products and services are designed to be accessible to all from the start, and this means accessibility is improved in a cost-effective way. However, this cannot eliminate attitudes and mental obstacles. Many of the products and services provided by museums are limited in content, are target group-specific and have been created as the result of interaction with various clients. At a very fundamental level, even when choosing objects for its collections, a museum is forced to make a choice about whose cultural heritage is included and which criteria are used for making a choice.

The talks at the conference also raised the question of equality in decision making. The only way to ensure that equality can be genuinely achieved is to include representatives of different population groups in the planning process. Where museums are concerned, this is a major change in fundamental principles, as the operations of museums have traditionally been based upon expertise in art history and history.

Where formal organisations, such as interest 
82 groups for people with disabilities, are concerned, the requirements for taking part and exerting an influence are already being structured. Many interest organisations have been involved in initiating accessibility work and drawing attention to the problem of inequality in cultural services and other public sector services. When it comes to people who are excluded socially and economically, it is much more difficult to create genuine opportunities for participation and for exerting an influence on the public service structures.

In encouraging participation by new population groups, it is important to draw on the opportunities created by the general trends in change. One recent phenomenon is that people are now generally interested in - and able to - participate and interact, rather than just be passive recipients. A panel discussion at the conference focused on whether we need to reassess the principle that the public sector is responsible for ensuring that the entire cultural heritage is accessible to all. Perhaps access could to some extent be attained through civic activity, by service users coming together and being active? Then again, this could prove a problem, because if culture is considered a fundamental right, then the ability to participate in it must not depend on civic activity. Whatever the case may be, drawing attention to the cultural heritage is becoming an increasingly central task of museums.

The primary goal of the conference was to open up new perspectives, to question prevailing views and to provide inspiration for promoting genuine accessibility to museums. In our capacity as arrangers of the conference, we wanted to create an environment that encouraged interaction between the participants. The relaxed atmosphere made it easy for the participants to express their opinions and to talk to others, including getting feedback on their ideas. The conference was conceived as a forum for shared expertise. The participants all brought a unique knowledge and expertise and everyone worked together to find solutions to questions that we face today. One of the ways in which we encouraged discussion was to hide questions in the napkins at the conference dinner, so as to give people ideas for how they could reflect on what they had heard and learned during the day and to provide topics of conversation with the others at their table. The programme for the conference dinner conveyed the strong and unique voice of minority groups, with sign-language rap music and visual arts on a theme of the lives of women with disabilities. The art programme contained a question in itself: Do society and museums today offer everyone equal opportunities?

The conference publication will be available in January at www.cultureforall.info.

\section{*Elina Anttila \\ Curator, PhD (Art History) \\ The National Museum of Finland \\ elina.anttila@nba.fi \\ The National Board of Antiquities, PO. Box 913, 00101 Helsinki \\ tel. +358-9-40509309}

* Sari Salovaara

Project Advisor

Bachelor of Arts (Art Education)

The Finnish National Gallery,

Kaivokatu 2, 00100 Helsinki

sari.salovaara@fng.fi 
INTERNATIONAL CONFERENCE IN HELSINKI PONDERS ACCESSIBILITY

*Leena Tokila

Education Coordinator, Master of Arts

(Ethnology), Bachelor of Arts (Education)

Finnish Museums Association, Annankatu 16 B

50, 00120 Helsinki

leena.tokila@museoliitto.fi 